\title{
Defects in rails
}

\author{
N S MISHRA, V RAMASWAMY and SANAK MISHRA \\ R \& D Centre for Iron \& Steel, Steel Authority of India Limited, \\ Ranchi 834002 , India \\ MS received 12 February 1984: revised 14 November 1985
}

\begin{abstract}
The performance of rails in service is greatly influenced by the presence of metallurgical defects. Hydrogen-induced shatter crack is the mosi prominent among these and has been discussed in detail. Principal causes of rail failure have been outlined and different types of defects leading to failure of rails during service have been documented. Wear of rails which accounts for reduced life has been considered. Influence of microstructure on wear rate has been described.
\end{abstract}

Keywords. Defects in rails; shatter cracks; detailed fracture; shelling; head-checks; dark-spots; wear.

\section{Introduction}

Resistance to structural failure as well as excessive wear is the major criterion involved in the assessment of the structural integrity of rails. In addition, serviceability of rails profoundly depends on the presence of defects. An increase in performance-demands in the present day railway system requires that the defect population should be kept at a level commensurate with safety and continued reliability.

Historically, in railroad industry, the term 'defect' has been associated with some visible artefacts, e.g., fissures developed during service. Customarily, in physical metallurgy this term is used in relation to crystallographic imperfections such as dislocation, stacking fault etc. This has been mentioned in order to avoid confusion in the use of the term in two entirely different contexts.

Defects may form intrinsically during processing or may be initiated during service. These are accordingly classified as material defects and service defects, respectively. A material defect acts as a nucleus and its subsequent growth under the prevailing loading conditions during service leads to the formation of the latter kind of defect.

Among material defects, hydrogen-induced shatter cracks are the most important in $\mathrm{p}_{\mathrm{c}}$. litic steels and this has been described in $\$ 2$ of the present study. An attempt has been made in $\$ 3$ to document the defects which frequently occur in rails during service. A significant portion of the railway maintenance expenditure is 
accounted for by the wear of rails, therefore, a better understanding of wear mechanisms might result in enormous savings. This has been discussed in $\$ 4$.

\section{Material defects}

The presence of subsurface defects of critical size leads to fracture during service. A majority of defects form during solidification and subsequent processing to the final products. Casting defects such as inclusions, blow holes, cavities and pipes etc. are well-known since the very early days of steelmaking. However, during the thirties, a defect known as shatter crack gained prominence. During this period, which witnessed a drastic increase in traffic density in all the railway systems, transverse fissures in rails were found to occur at an alarming rate and shatter cracks were identified as nucleating sites for these fissures which propagated under the influence of rolling-contact fatigue. These small fissures are highly elongated and act as sites for stress concentration like any longitudinal cracks. Their study, therefore, deserves special attention.

\subsection{Shatter cracks}

Shatter cracks, alternatively known as hydrogen flakes, appear round or oval-shaped along the fractured surface. Their size varies from $0 \cdot 1$ to $25 \mathrm{~mm}$. Along the section perpendicular to the crack, these can be observed as thin fissures or hairline cracks. Figure 1 shows a photomacrograph from the head portion of a

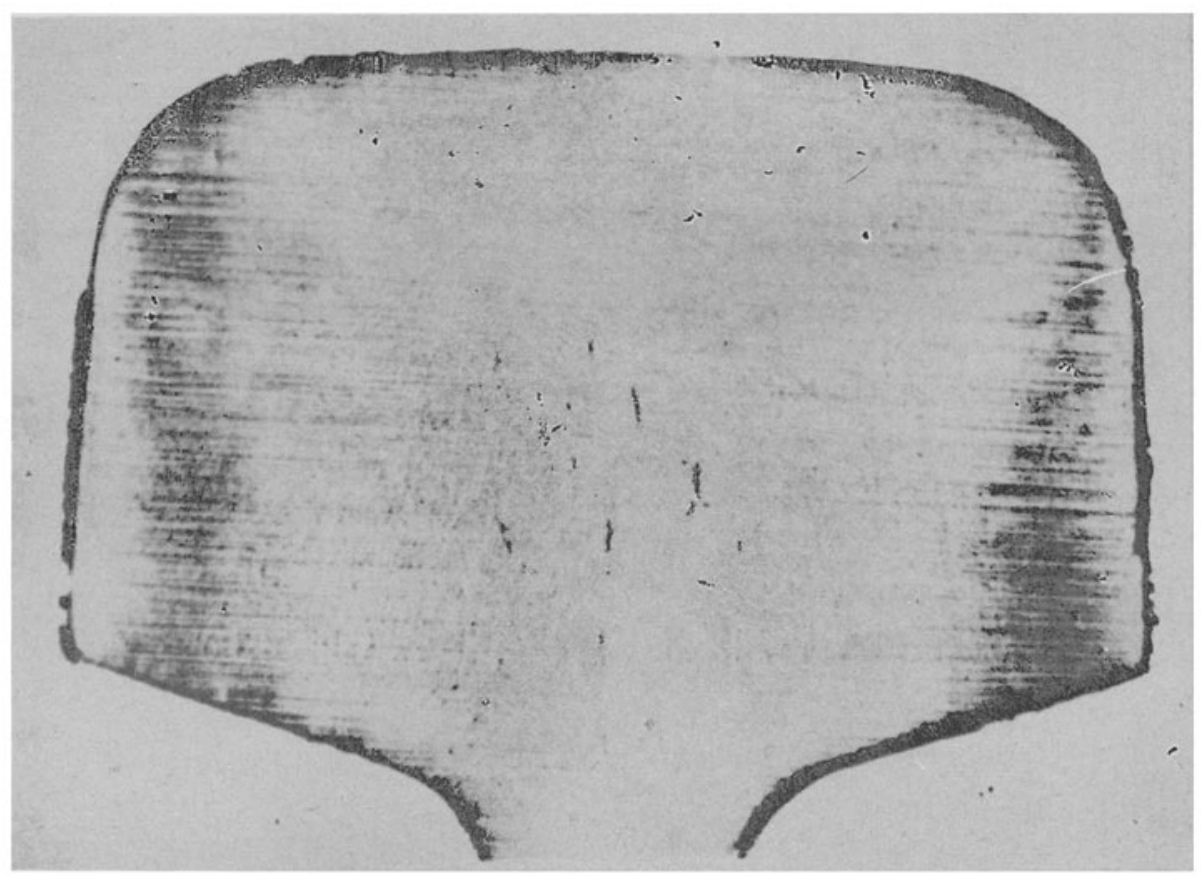

Figure 1. Photomacrograph of rail showing hydrogen-induced hair line cracks (Stone \& Steels 1978 , p. 21). 
rail (Stone \& Steels 1978 , p. 21 ). Several hair-line cracks of $\approx 3000 \mu \mathrm{m}$ longitudinal dimension may be noticed. It is also interesting to note that these cracks mostly exist in the rail head portion. The propagation of these cracks is usually transcrystalline, though larger cracks have been found to be intercrystalline in nature as well (Andrew et al 1942).

Controversies persist as to the origin and mechanism of the formation of shatter cracks (Smialowski 1962, p. 327). Bennek et al (1935) were the first to correlate the occurrence of shatter cracks with the decreasing solubility of hydrogen in steels during cooling. Structural transformation and temperature gradient induced stresses further aid the process. Phase transformation from $\gamma(\mathrm{fcc}) \rightarrow \alpha(\mathrm{bcc})$ at $A r_{1}$ $\left(\approx 725^{\circ} \mathrm{C}\right.$ ) results in drastic decrease in the solubility of hydrogen (McGannan 1964 , p. 289) which accelerates the process of crack initiation, whereas stresses developed due to a temperature gradient along the cross-section help in the propagation of the cracks. Since the head portion of the rail is relatively thick, shatter cracks have been found to occur extensively in this portion due to the high thermal gradient.

The possible mechanism of formation of flakes has been studied by many investigators (Scharader \& Pranjape 1954; Meskin 1950; Aichholzer 1928). A theory which gained wide acceptance postulates that at increased cooling rates, complete hydrogen removal from the supersaturated solution cannot be insured by diffusion. Due to the precipitation of gases within the steel, an enormous amount of pressure builds up which might locally exceed the fracture strength of steel leading to the formation of small ruptures. The pressure of hydrogen liberated in the steel upon rapid cooling has been estimated to be in excess of $10^{6} \mathrm{~atm} *$ (Scharader \& Pranjape 1954).

A certain time lag for initiation of cracks has been envisaged by Andrew et al (1942). Once the embryo is created, its growth is a very fast process. Hydrogen diffusion rate, the probability of hydrogen atoms combining and forming molecular gas, as also the critical size of the embryo, are the factors which influence the incubation period of embryo formation (Meskin 1950).

Theoretical computation pertaining to energy released during the combination reaction of hydrogen atoms $\left(\mathrm{H}+\mathrm{H} \rightarrow \mathrm{H}_{2}+2.8 \times 10^{8} \mathrm{~J} / \mathrm{kg}\right.$ of $\left.\mathrm{H}_{2}\right)$ has been carried out by Meskin (1950) for steel containing $10 \mathrm{ppm}$ hydrogen. Total energy equivalent to $7.78 \times 10^{9} \mathrm{~J} / \mathrm{m}^{2}$ would be liberated for an embryo of size $10^{-5} \mathrm{~m}$. It is to be noted that the energy released per unit area is inversely proportional to the square of the linear dimension of the embryo. Assuming that only $0 \cdot 1 \%$ of the total energy is consumed in the process of crack initiation and allowing for a fraction of this energy $(\approx 25 \%)$ to be dissipated as heat, $5.8 \times 10^{6} \mathrm{~J} / \mathrm{m}^{2}$ still remains to be expended locally. As the reaction is very fast and could be completed within $10^{-4} \mathrm{~s}$, the energy evolved is transmitted as shock waves striking the surrounding metal. Flake formation becomes a possibility as the energy of the shock wave is far in excess of the impact stiength of steel which is usually $30 \times 10^{4} \mathrm{~J} / \mathrm{m}^{2}$ in the case of rail steels. Meskin (1950) further elaborated that flake formation is facilitated in the presence of internal notches e.g. non-metallic inclusions, martensitic zones etc.

Andrew et al (1942) made an interesting observation which further confirmed the key role played by hydrogen in the formation of shatter cracks in steels. Flaky steel

\footnotetext{
$* 1 \mathrm{~atm}=1.0133 \times 10^{5} \mathrm{~Pa}$
} 
specimens were rapidly heated to $300^{\circ} \mathrm{C}$ and $650^{\circ} \mathrm{C}$. White ferrite veins surrounding the crack were observed in the former whereas globular carbides were noticed in the latter. The authors conjectured that hydrogen contained within the cracks reacted with carbon at $300^{\circ} \mathrm{C}$ to produce methane which led to local decarburization. At $650^{\circ} \mathrm{C}$, the unstable methane dissociates and free carbon is utilized to produce carbides. Therefore it may be inferred that the carbide segregation around the crack is a result and not the cause of crack formation as suggested in previous studies (Aichholzer 1928). Interestingly, the formation of methane contributes an additional energy of $21 \times 10^{7} \mathrm{~J} / \mathrm{kg}$ of hydrogen (Meskin 1950) to the process of crack propagation.

The parameters which influence the susceptibility to shatter cracks in steels are of fundamental importance. An increase in hydrogen content increases sensitivity to flake formation. A hydrogen content upto $3 \mathrm{ppm}$ is considered safe. The amount of gas retained that could possibly contribute to flaking depends on the section size, its chemistry and the rate of cooling. Tendency towards flaking is greater in heavier sections and in steels with higher carbon contents. An increase in manganese to carbon ratio increases the sensitivity to shatter cracks. Ironically a higher sulphur content reduces susceptibility to flake formation (Heller et al 1972). Figure 2 demonstrates the influence of sulphur on the sensitivity to shatter cracks in $0.53 \% \mathrm{C}-1.28 \% \mathrm{Mn}$ rail steel at different hydrogen levels. As is evident from the figure, increasing the sulphur content decreases the number of flakes formed, whereas the reverse is the trend with hydrogen. This phenomenon could be ascribed to increased activity of hydrogen in steel in the presence of sulphur (also phosphorous), thereby decreasing hydrogen solubility $(\approx 18 \mathrm{ppm}$ per $1.0 \%$ increase in sulphur content, McGannan 1964, p. 289).

Addition of alloying elements has a pronounced effect on the susceptibility to flaking. Usually, most of the elements increase the activity of hydrogen in steel (McGannan 1964, p. 289), therefore, as a rule their addition should render steels less prone to shatter cracks. The other criterion is associated with variations in the diffusion rate of hydrogen atoms consequent upon structural change. Mobility of hydrogen is greatly diminished when phase transition from $\gamma$-iron to $\alpha$-iron occurs.

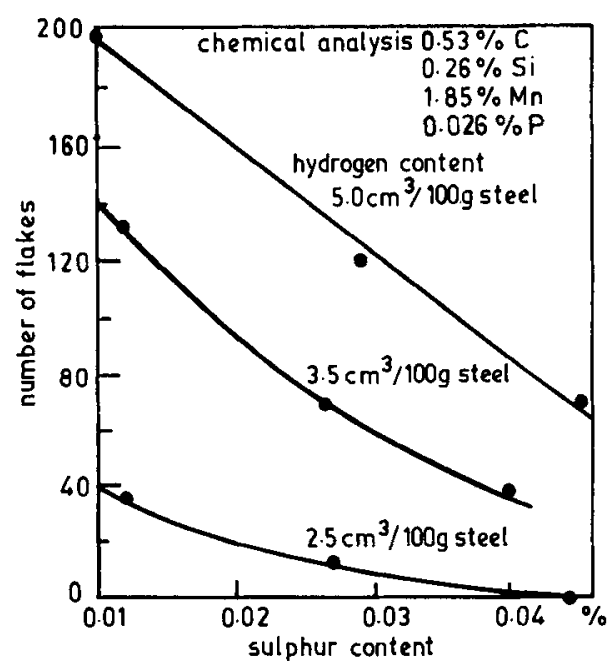

Figure 2. Influence of sulphur content on flake formation for various hydrogen contents in 0.53 C- $[.28 \mathrm{Mn}$ rail steel (Heller et al 1972). 
Therefore, those elements which enhance $\gamma \rightarrow \alpha$ transition temperature $\left(A c_{1}\right)$ should reduce the sensitivity. This is because most of the hydrogen atoms would escape out of the steel owing to greater mobility at increased temperature. In addition, those elements which decrease the temperature of martensite transformation $\left(M_{s}\right)$ shall increase the susceptibility to flaking since at lower temperature less mobile hydrogen getting entrapped into already stressed martensite needles or internal notches (as a consequence of change in specific volume) becomes a possibility. This implies that normal C-Mn rails with high hydrogen contents are extremely vulnerable to shatter cracks.

Meskin (1950) suggested that relatively stable hydride forming elements, e.g., Si, $\mathrm{Cr}, \mathrm{V}, \mathrm{Ti}$ and $\mathrm{Nb}$, generally do not partake in the flaking process since chemically bound hydrogen is rendered immobile. Flake formation could be suppressed if the concentration of these elements is considerable but concurrent is the risk of hydrogen embirttlement. From the foregoing it may be concluded that rail steels alloyed with chromium, vanadium and niobium are less sensitive to flaking than standard C-Mn rails.

Susceptibility to flaking is enhanced drastically by employing rapid cooling. This is due to the combined effects of an increased degree of supersaturation and a drop in the temperature of flake formation. The former provides an increased number of hydrogen atoms for participation in the recombination reaction, whereas the latter is accompanied by an enormous decrease in the diffusion rate of hydrogen atoms, thus inhibiting their escape. Depending on the chemistry of the rails and the cooling rate employed, shatter cracks usually occur in the temperature range $150-250^{\circ} \mathrm{C}$ (Dubovoi 1950).

Formation of flakes could be suppressed if slow cooling is employed. A slightly higher cooling rate $\left(\approx 15^{\circ} \mathrm{C} / \mathrm{hr}\right)$ is admissible in the temperature range where a phase change occurs $\left(750-500^{\circ} \mathrm{C}\right)$; but cooling needs to be extremely slow (less than $8^{\circ} \mathrm{C} / \mathrm{hr}$ ) while passing through the temperature of flake formation $\left(450-150^{\circ} \mathrm{C}\right)$. The influence of cooling rate on the formation of flakes has been studied by Cramer \& Bast (1939). Figure 3 has been adapted from their work (Cramer \& Bast 1939a) and it can be seen from the figure that formation of flakes could be prevented by cooling rail steel at the rate of $45^{\circ} \mathrm{C} / \mathrm{hr}$ in the temperature range $560-380^{\circ} \mathrm{C}$ and

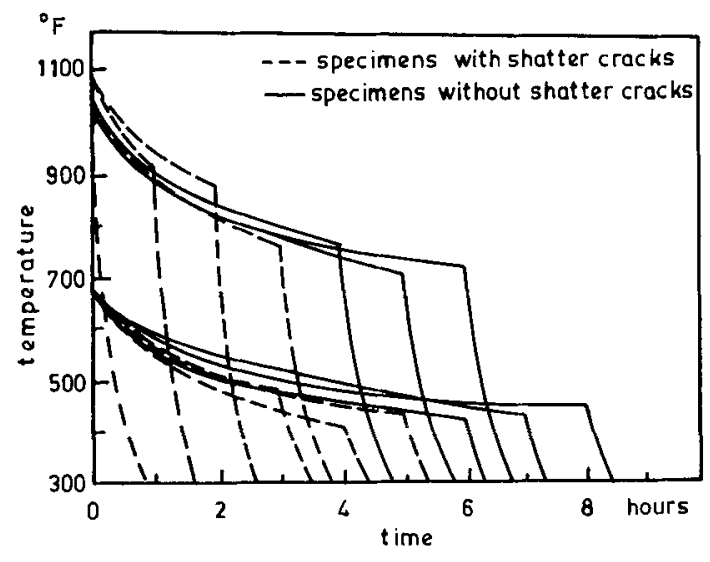

Figure 3. Influence of cooling rate on the formation of shatter cracks (Cramer \& Bast 1939a). 
thereafter at the rate of $20^{\circ} \mathrm{C} / \mathrm{hr}$ down to $150^{\circ} \mathrm{C}$. However, this observation allows higher cooling rates in comparison to those opined by Dubovoi (1950).

Vacuum treatment of molten steel offers another method for suppressing the formation of cracks. By exposing the liquid steel to low pressure conditions the hydrogen content could be brought down to a harmless level $(\approx 3 \mathrm{ppm})$. This, in turn, would reduce the susceptibility to flaking.

\section{Service defects}

Internal flaws in the form of material defects act as nuclei for the propagation of cracks under the influence of rolling-contact fatigue. Their unrestricted growth leads to detailed fracture otherwise known as service defects in railroad industry. These defects have been found to occur along transverse as well as longitudinal cross-sections of the rail. Depending on the microstructure and the severity of the stresses, a certain critical size of the initial crack is imperative for its growth. A majority of the service-developed defects have been identified as of the fatigue type initiated from internal notches such as shatter cracks and inclusion stringers (Sonnon et al 1978, p. 99). Additionally, contact rolling may cause plastic flow of metals at the running surface or in its vicinity. This leads to the formation of several types of surface defects, shelling and flaking being the most prominent among them. The frequency of occurrence of these defects and their severity depend upon speed, curvature and axle load experienced by the track.

Macroexamination of a fractured surface is often utilized to identify the mode, mechanism and growth rate of the fracture. An exhaustive survey of the service defects has been dealt with elsewhere (Rail Defects Manual 1964). A detailed discussion of some of the defects which frequently occur in tracks are presented here.

\subsection{Detailed fracture}

Customarily in railroad industry the term 'detailed fracture' has been associated with the type of fissure resulting in complete separation (see, for example, Rail Defects Manual 1964).

3.1a Transverse fissure: A transverse fissure is a progressive fracture initiated from a sub-surface nucleus. The plane of propagation is normal to the running surface. The initial crack size is the dominating factor in deciding its growth rate. It is slow up to. a size of $20-25 \%$ of the rail cross-section and becomes rapid thereafter as shown in figure 4. Several growth rings can be spotted around the nucleus of size $\approx 10 \mathrm{~mm}$, indicating the growth process. It is hazardous as it tends to occur at severat places in rails of the same heat. This is a precursor of certain derailment (Marich et al 1978).

The growth pattern for transverse cracks in different types of rail steels have been monitored by Marich $(1979$, p. 23). The investigation consisted of measuring the semi-major axis of cracks at intervals of one million cycles from an initial size of $10 \mathrm{~mm}$ (major axis) till critical sizes for brittle failure were reached. Crack contours were drawn from the above data (figures $5 \mathrm{a}, \mathrm{b}$ ). The growth patterns reveal that 


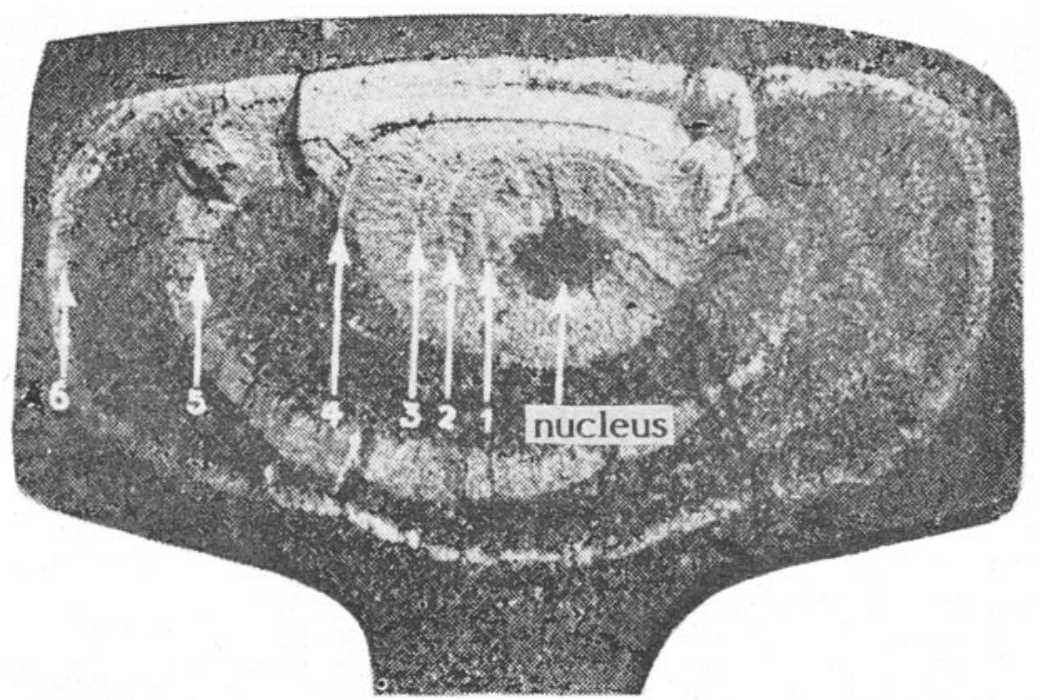

Figure 4. Crack growth rings in transverse fissure (Rail Defects Manual 1964).

while contours are more widely spaced for standard (Std. C) and through-hardened (TH) rails, the contour intervals are narrow in $\mathrm{Cr}-\mathrm{V}$ rails (type 2). Also the critical sizes for catastrophic failure vary widely in the above rails. It may be noticed that chrome-vanadium rails show the smallest critical crack size for growth. This leads to the inference that although chrome-vanadium rails exhibit the longest crack growth time, the detection of critica! size for catastrophic failure due to transverse fissure becomes difficult by employing the current practice of ultrasonic inspection.

Microexamination of the transverse fracture surface often discloses the presence of characteristic fatigue striations. Figure 6 is a scanning electron micrograph incorporating simultaneously the etched as well as the fractured sections which are normal to each other. One to one correspondence could be discerned between the striation and pearlite lamellar spacings. In addition, the direction of crack propagation is also identically oriented with the two. Sonnon et al (1978, p. 99) further observed that similar relations existed in a majority of service-developed defects as well as in fatigue specimens tested in the laboratory. These striations can provide information for locating the origin of cracks.

3.1b Compound fissure: This type of detailed fracture entails crack initiation and propagation parallel to the running surface of the rail-head causing horizontal separation. At some stages, transverse separation also occurs as the advancing crack-edge changes planes and crack-growth continues in the transverse crosssection. Service failure of this type usually involves complete separation of the rails across head, web and base.

Figure $7 \mathrm{a}$ is a typical macro-fractograph of a compound fissure. The bright circular region along the transverse plane is indicative of fatigue type crack propagation. The beach mark in this area can be used to locate the origin of the crack. Macroexamination of the defect origin by scamning electron microscopy revealed a smooth featureless surface (figure 7 b). Fatigue striations could be 


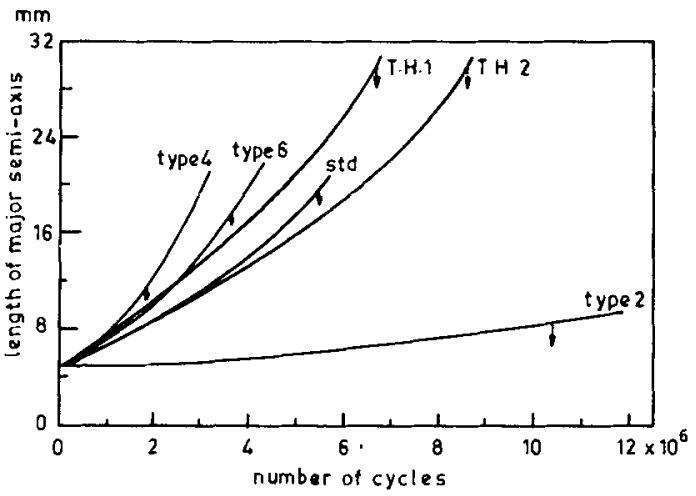

(a)

(b)
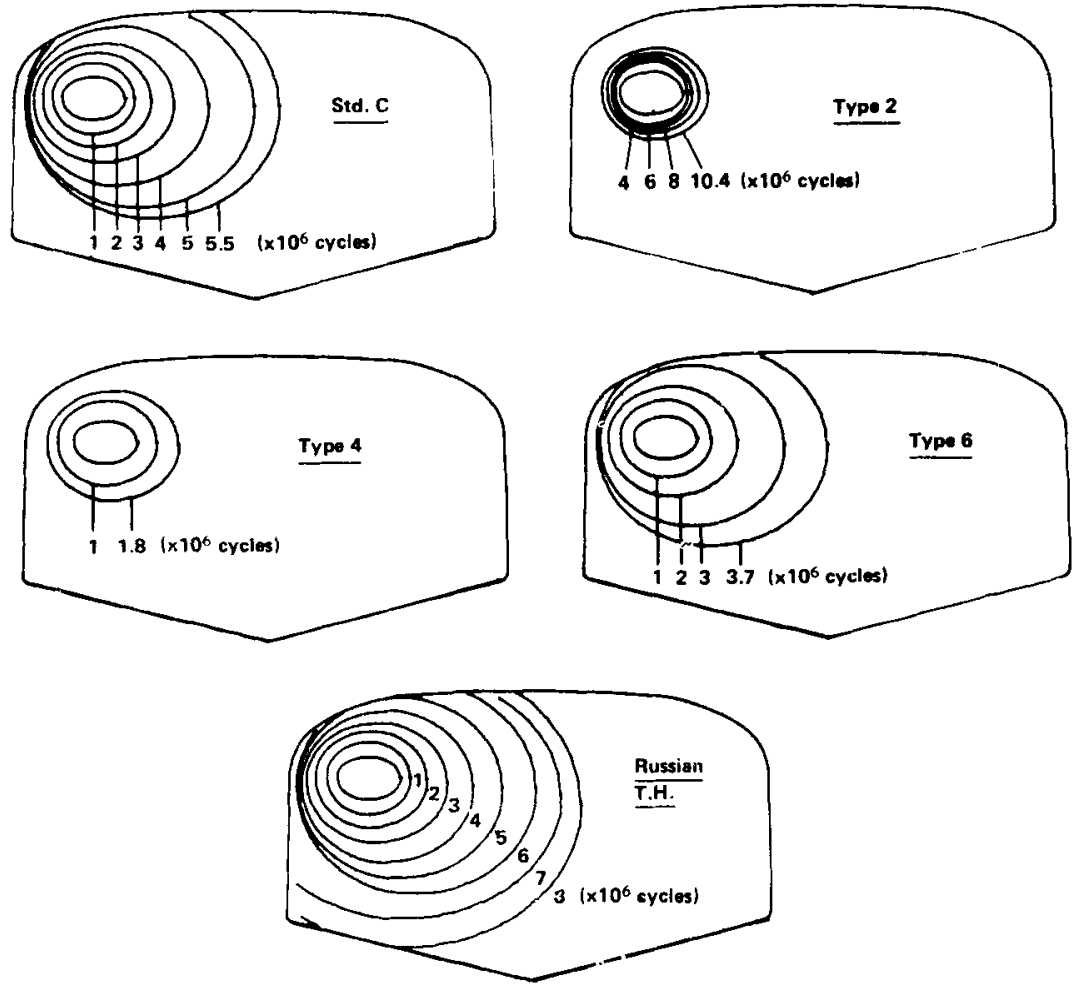

Figure 5. a) Defect growth rates, and b) defect growth pattern in different types of rail steels (Marich 1979, p. 23).

noticed in some locations as weil. Figure $7 \mathrm{c}$ is the optical photomicrograph of the transverse cross-section around the crack origin. Several micro-voids could be observed signifying crack initiation by micro-void coalescence. These micro-voids could be clearly discerned as shatter cracks.

3.1c Split head: A progressive fracture may occur longitudinally in rails in transverse as well as in horizontal planes. In a vertical split, separation starts along 


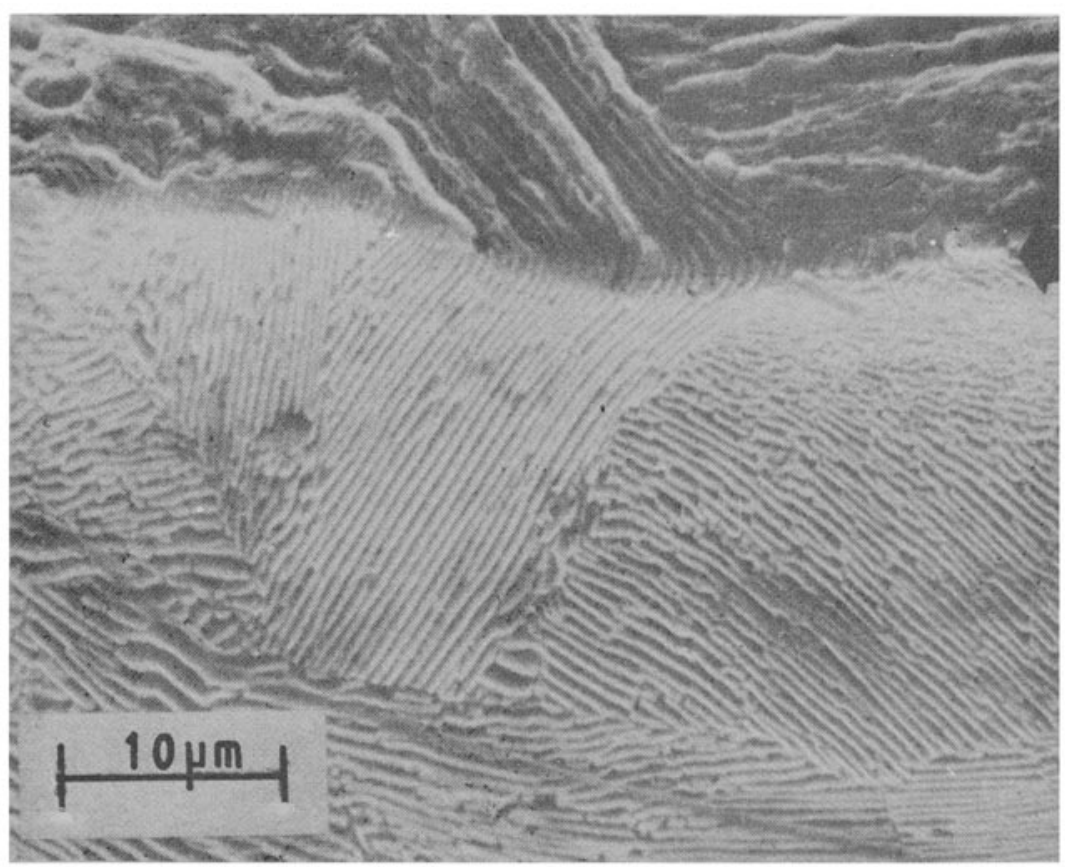

Figure 6. Scanning electron micrograph incorporating simultaneously the microstructure as well as fracture topography of rail steel showing one to one correspondence between fatigue striations and pearlite lamellae. Arrow indicates direction of crack propagation (Sonnon et al 1978. p. 99).

a seam and propagates vertically through the cross-section. It is easy to detect them as dark streaks on the running surface. Their presence may cause dropping of the head which may occur either in the field side or the gauge side, the latter being more hazardous. Similarly, a horizontal split head is a longitudinal rupture of the head parallel to the running surface.

An example of a split head rail has been displayed in figure $8 \mathrm{a}$. Occurrence of longitudinal separation parallel to the running surface followed by a transverse fissure is apparent from the figure. Scanning electron metallography, in conjunction with energy dispersive spectra and X-ray analysis, disclosed calcium aluminate inclusions surrounded by iron-oxide particles at the crack initiation sites as shown by the arrow along the fractured transverse plane (figure $8 \mathrm{~b}$ ). The formation of iron-oxide is the result of atmospheric corrosion and this being brittle in nature might have assisted in the propagation of cracks. Also included in this figure at the top is the fractograph showing numerous micro-voids indicative of crack propagation via the ductile mode.

Identical observations were made in the horizontal section parallel to the running surface. Figure $8 \mathrm{c}$ is the optical photo-micrograph from the above region showing copious amounts of calcium aluminate inclusion stringers present at the defect origin. The stringers are almost perpendicular to the rolling direction as indicated by the arrow. Besides inclusions, the presence of longitudinal seams and segregation have also been linked with the occurrence of such failures. 

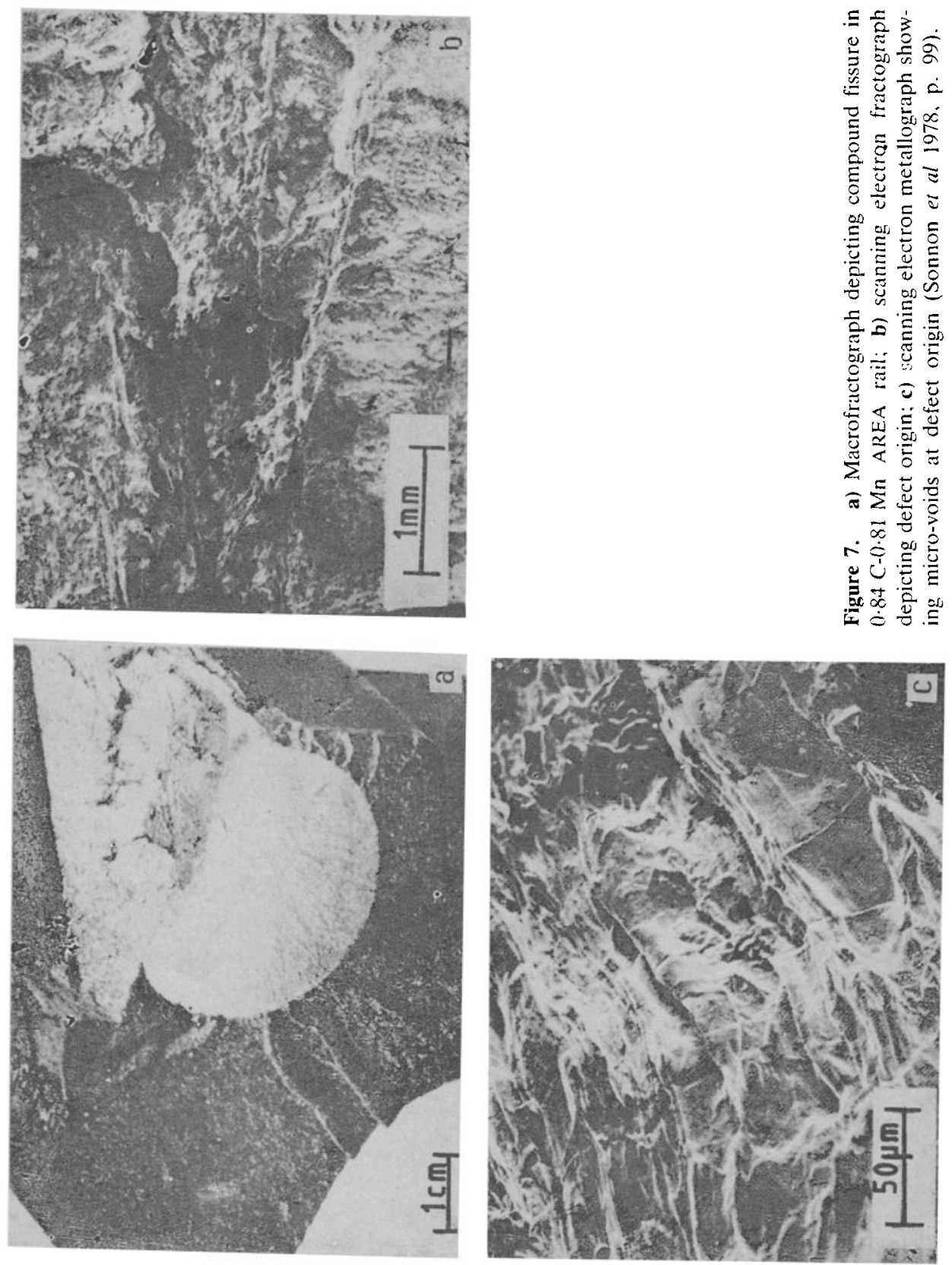


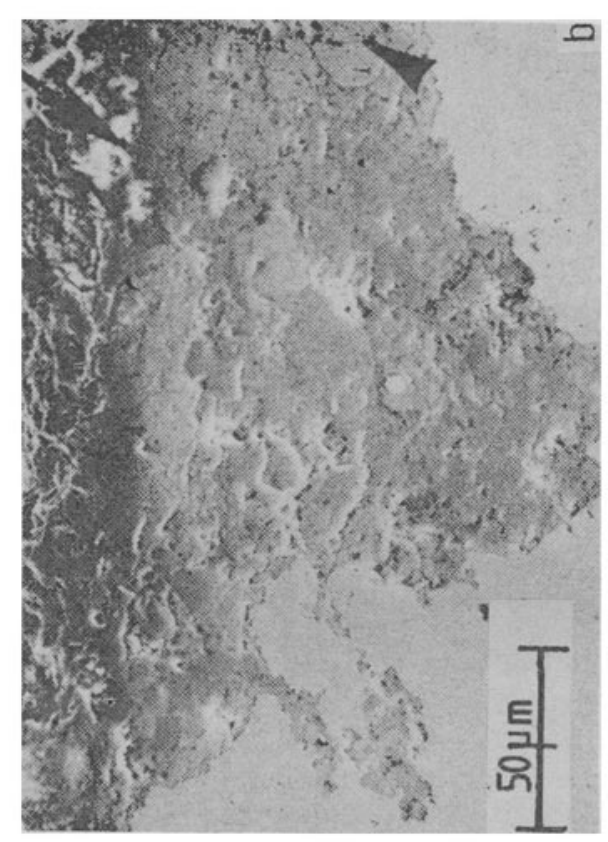

ن

20.

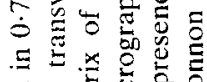

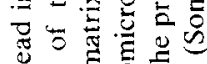

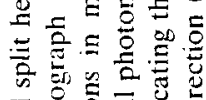

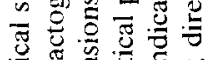
을

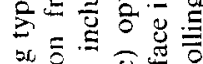

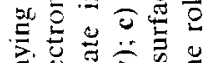
踏比

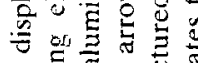

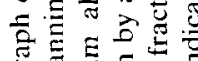

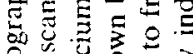

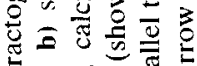

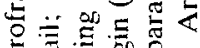

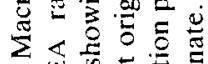

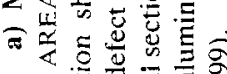

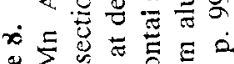

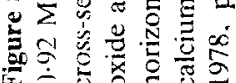
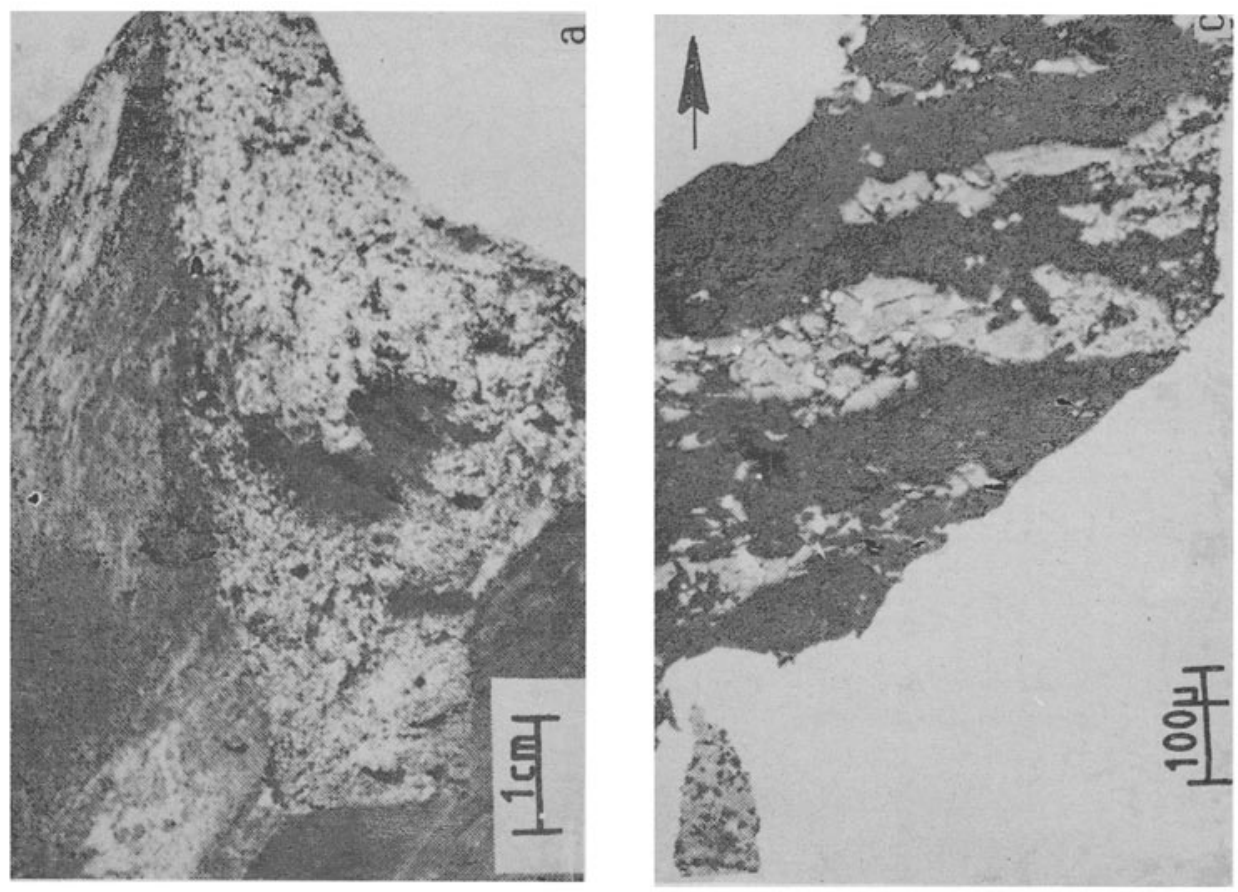
3.1d Engine burn: Engine burn sometimes becomes the source of a progressive fracture causing transverse separation as shown in figure 9. It usually occurs in combination with shallow horizontal separation where the zone of burnt metal separates from rail head metal. Engine burn is caused by the excessive heating of the rail surface by slipping engine driver wheels. Subsequent rapid cooling gives rise to thermal fatigue which in turn leads to crack initiation. Further growth of cracks is aided by successive impact of wheels. Occasionally the friction of locomotive drivers leaves scars on the rails as a result of overheating. This is a potential source of defects known as dark-spots.

In addition to the above-mentioned defects, other types of progressive fracture might occur in the web as well as in the base of rails. Prominent among such defects are head and web separation, split web and piped web. Two principal types of base defects are broken base and web-base split.

\subsection{Surface defects and associated fractures}

3.2a Shelling: When a rail is subjected to heavy axle load, the metal at and around the running surface undergoes plastic deformation and subsequent failure occurs in the sub-surface shear mode. Besides axle load, the speed of the rolling stock and the curvature of the track are the important parameters which determine the amount of flow, as they contribute significantly to the increase in frictional forces between wheels and rails. Enhanced friction introduces additional shear and flow

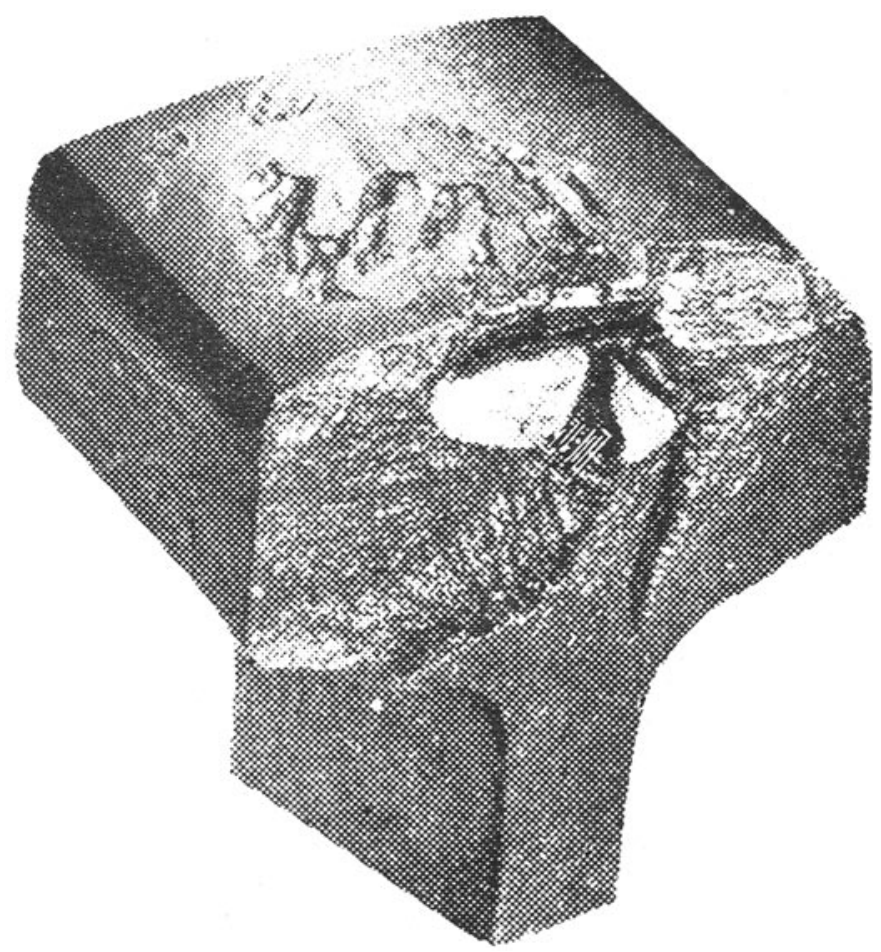

Figure 9. Engine burn fracture showing small transverse separation (Rail Defects Manual 1964). 
becomes more rapid (Knupp et al 1978, p. 7). This effect is more pronounced in the high side rails at gauge corners, since these locations experience increased stresses induced by centripetal forces.

Shelling first came into prominence during the forties when it became imperative to use high capacity $(\approx 50-70 \mathrm{t})$ cars (Kumar et al 1982). Severe shelling often leads to detailed fracture. Figure 10a shows the detailed fracture from shelling which originated from a longitudinal separation close to the running surface of the rail-head. Subsequently, the plane of separation took a downward turn and became almost normal to the running surface, resembling transverse fissure. Microexamination of the origin of the crack revealed the presence of particles containing calcium and aluminium. Figure $10 \mathrm{~b}$ shows discontinuous calcium aluminate inclusion stringers at the defect origin.

The nature and amount of plastic flow caused by contact stresses between the rails and wheels has been investigated theoretically by Kumar \& Rajkumar (1980) and also experimentaliy by Kumar et al (1982). Their calculations based on the Hartzian elastic theory showed that under static normal loading conditions the contact stresses developed between rail and wheel are in excess of the local yield strength of rail steel resulting in plastic flow. The frictional forces associated with traction increase the amount of flow. Under the influence of successive wheel passages, progressive work-hardening takes place. Stress reversals are essentially elastic in nature and eventually a stage is reached when further plastic deformation becomes minimai. This ultimately leads to material failure.

The nature of plastic flow and initiation of cracks were investigated in detail by Ichinos et al (1978). Shelling in rails was simulated in the laboratory by conducting rolling-contact fatigue tests. A pair of cylindrical specimens representing rail and wheel were used in a Nishihara-type wear testing machine to reproduce rail-wheel contact. Their observations may be summarized as follows. Contact rolling leads to initiation of a linear crack at the contact surface. Subsequent sub-surface crack propagation occurs at an angle of $\approx 30^{\circ}$ to the direction of load movement. Propagation continues to a constant depth $(\approx 20 \mu \mathrm{m})$ and ultimately results in
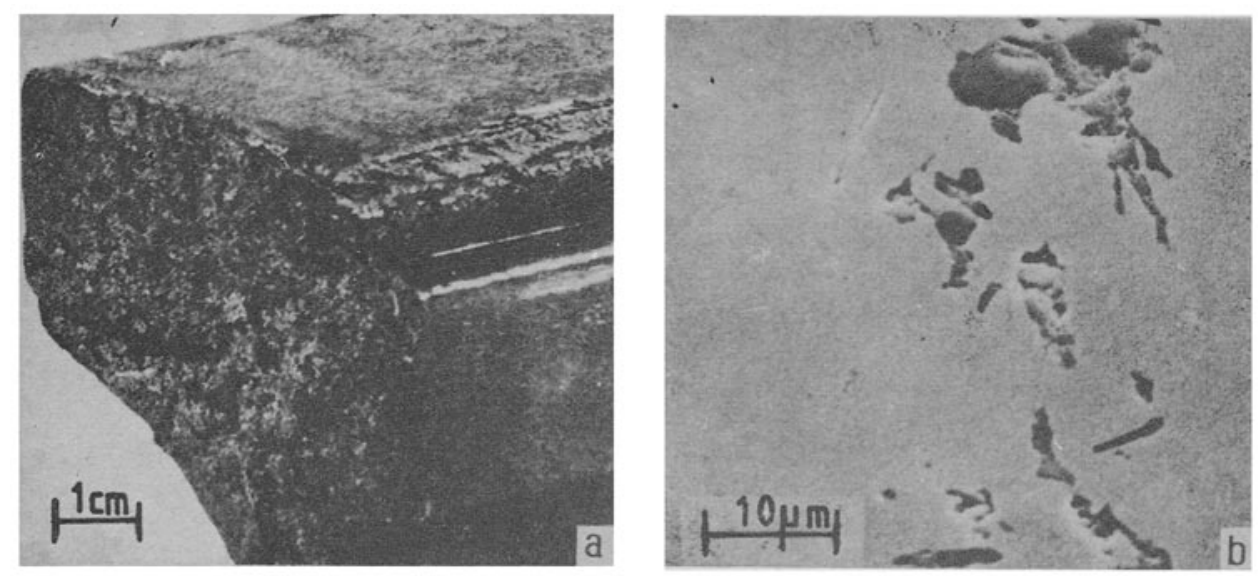

Figure 10. a) Detailed fracture from shelling; b) optical photomicrograph exhibiting discontinuous calcium aluminate inclusion stringers at the defect origin (Sonnon at at 1978, p. 99) 
shelling (figures $11 \mathrm{a}, \mathrm{b}$ ). The incubation period of crack nucleation and also the depth of shelling increase remarkably with increase in load and slipping. The latter has a more drastic effect. Any reversal of rolling direction not only decreases the propagation rate of the crack already initiated but also tends to close it. Repeated reversal of rolling directions leads to easy initiation of cracks and plastic flow becomes wave-like.

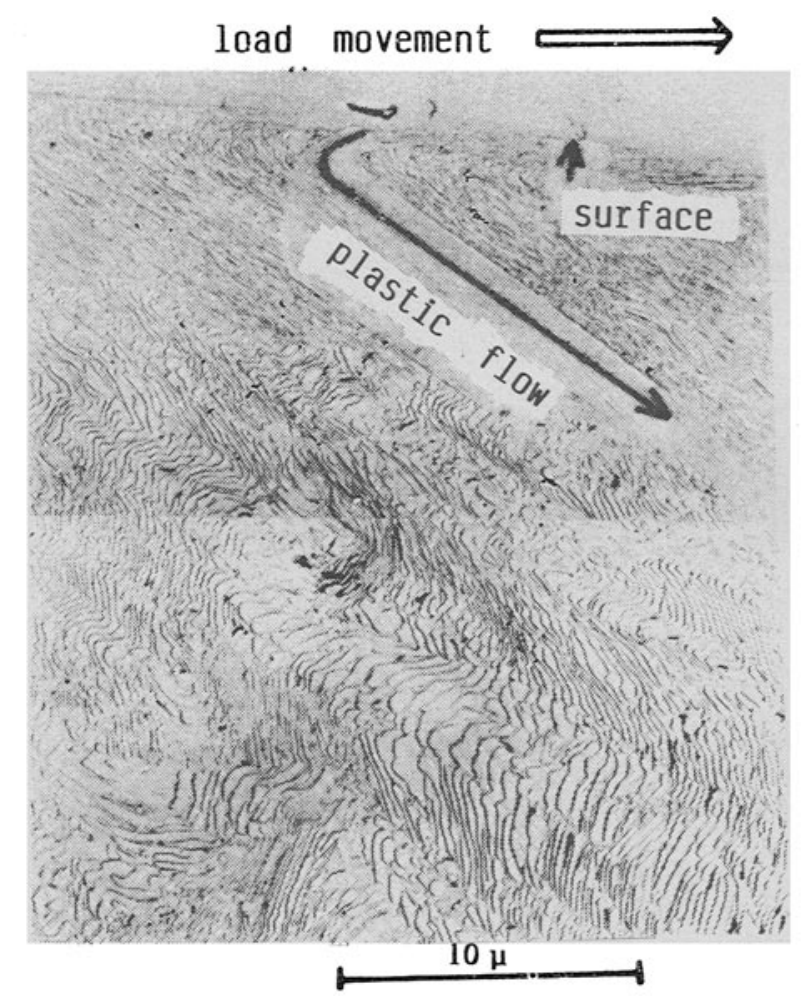

lood movement

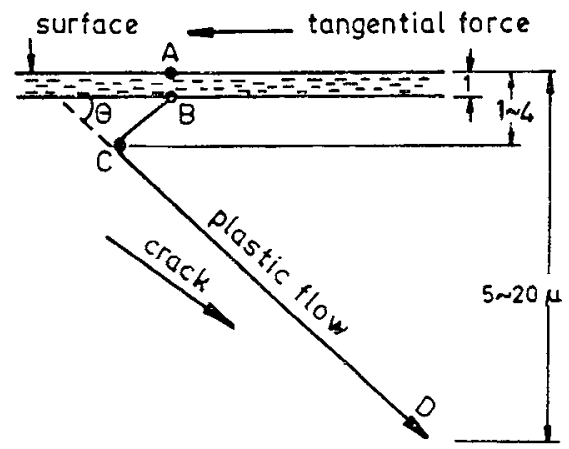

(b)

Figure 11. a) Optical photomicrograph exhibiting surface plastic flow by contact rolling; b) schematic diagram representing plastic flow penetrating the sub-surface upto a depth of $\approx 20 \mu \mathrm{m}$ (Ichinos et al 1978). 
3.2b Flaking: Flaking is very similar to shelling and is often confused with it. It occurs as a horizontal separation on the running surface of rails near the gauge corner in the form of scaling or chipping of small slivers (figure 12). It can be recognized by the appearance of horizontal hairline cracks. Though not a serious defect, it may develop into shelling, if allowed to persist.

Apart from shelling and flaking, two other types of contact fatigue defects, namely, head-check and dark-spot, have attracted attention recently (Masumoto et al 1978, p. 233). These have been found to occur in tracks which experience relatively lighter loads (less than eight tonnes).

3.2c Head-check: Figure 13a shows a series of sigmoidal defects on the gauge corner of the rail head, spaced at intervals of approximately 2-3 mm. Their occurrence is independent of traffic speed. Head-checks are formed predomiriantly in outer rails in curved sections of radii greater than $1000 \mathrm{~m}$. These defects do not grow to critical size and wear out quickly on tracks of smaller radii. Occasionally, head-checks have also been observed on tangent tracks and inner rails of curved tracks.

Masumoto et al (1978, p. 233) have considered the propagation of head-check defects and have divided the process into four stages as shown in figure 13b. The cracks become visible in stage $I$ with the passage of relatively lighter traffic $(\approx 10 \mathrm{GMT})$. A few of the cracks propagate towards the outside corner in stage II when the stress conditions are favourable. With increase in the passage of traffic the crack encompasses the entire running surface in stage III. Stage IV is the final brittle rupture when the defect area approaches $35-40 \%$ of the rail cross-section.

3.2d Dark-spot: Dark-spot occurs individually in contrast to head-checks which occur in groups. Whereas the formation of head-checks is independent of traffic speed, dark-spots develop on the running surface of tracks experiencing traffic

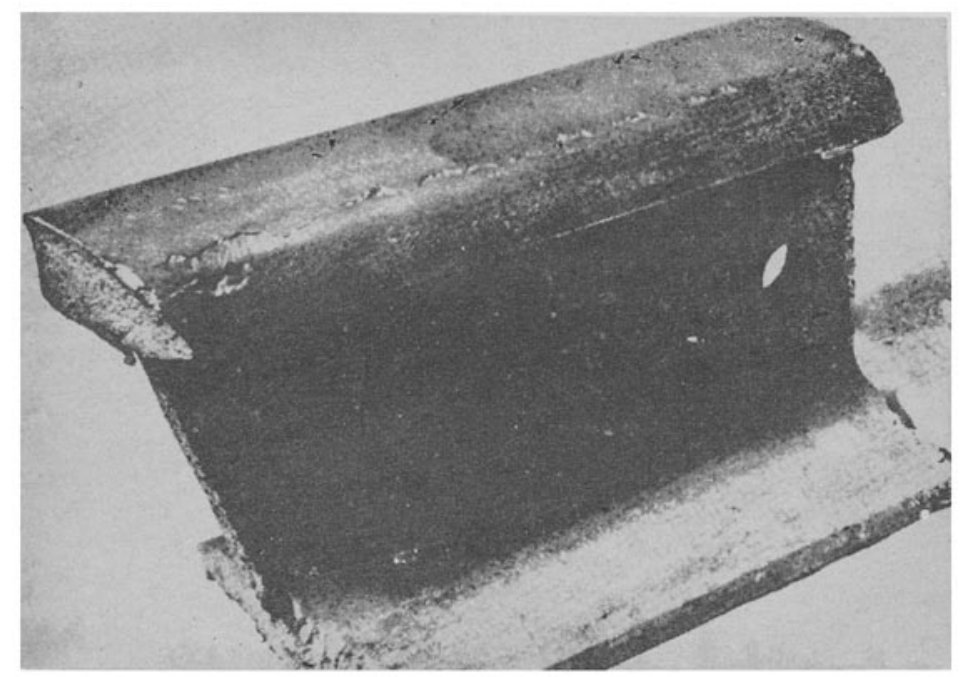

Figure 12. Macrofractograph depicting appearance of flaking in rail (Rail Defects Manual 1964). 
(a)

\section{rail No. 1768 - direction of traffic}
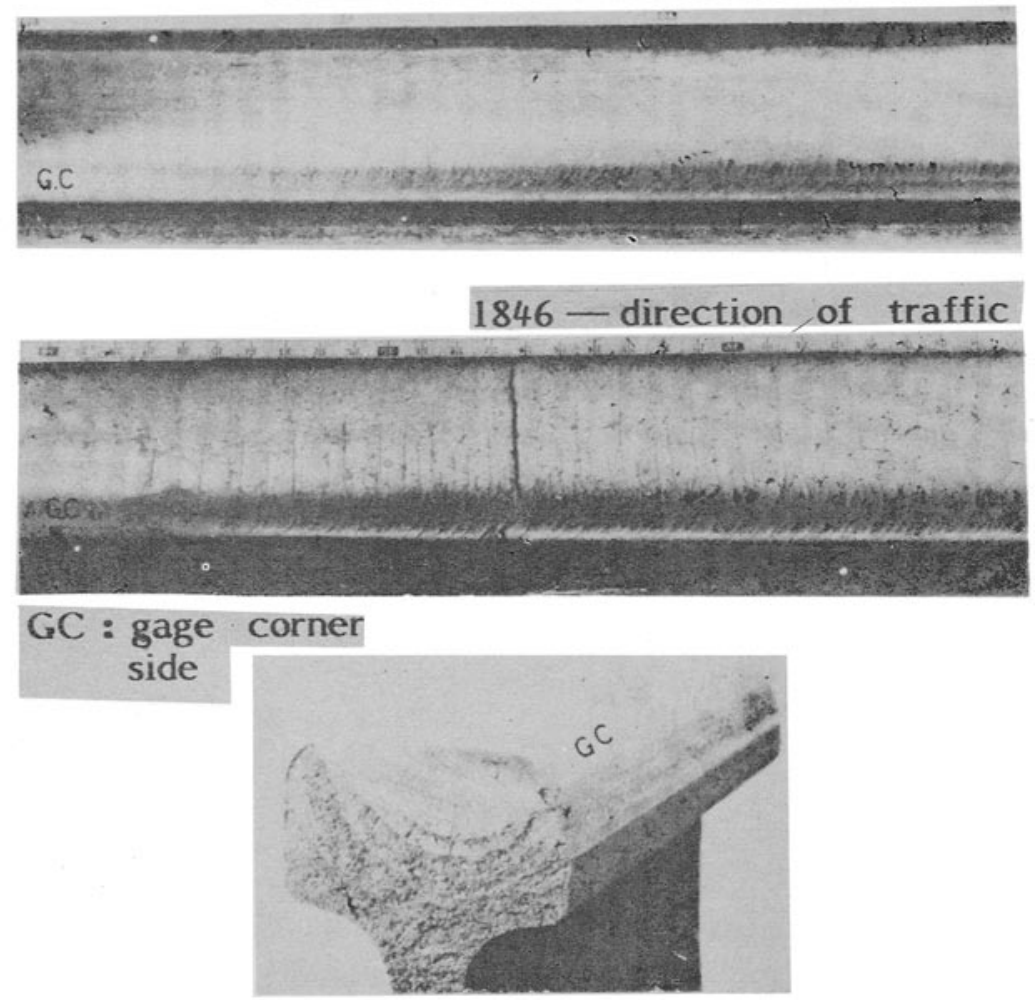

(b)

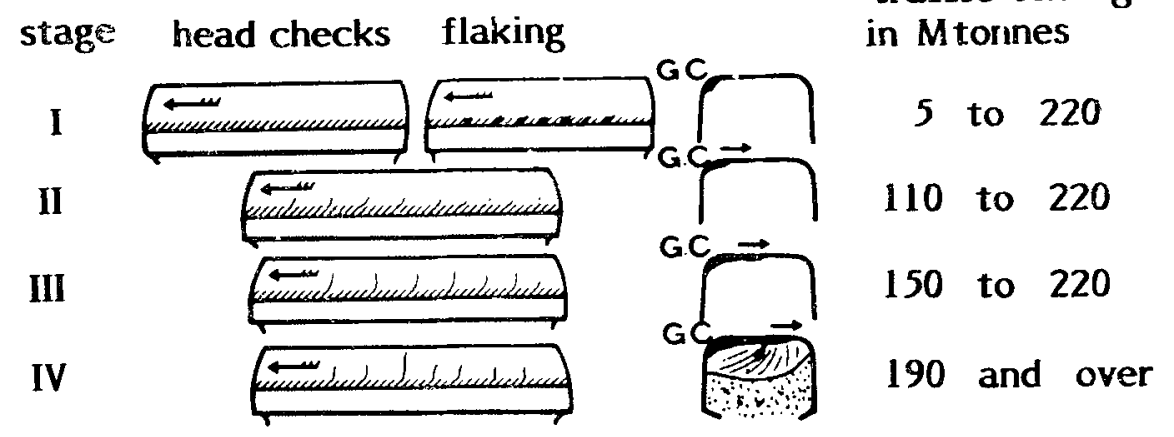

Figure 13. a) Macrophotograph showing series of S-shaped cracks as head-check defect on the gauge corner of running surface; b) schematic sketch indicating the growth process of head-check in different stages (Masumoto et al 1978, p. 233).

speeds greater than $150 \mathrm{kmph}$. They have been classified as types A, B and C depending upon the location of their occurrence, viz, near the gauge corner, central area, and outside corner, respectively (figure 14a).

The propagation process of dark-spots has been divided into four stages similar to that of the head-check. As shown in figure 14b in stage I, the crack initiated by contact rolling at the surface penetrates into the sub-surface and spreads 

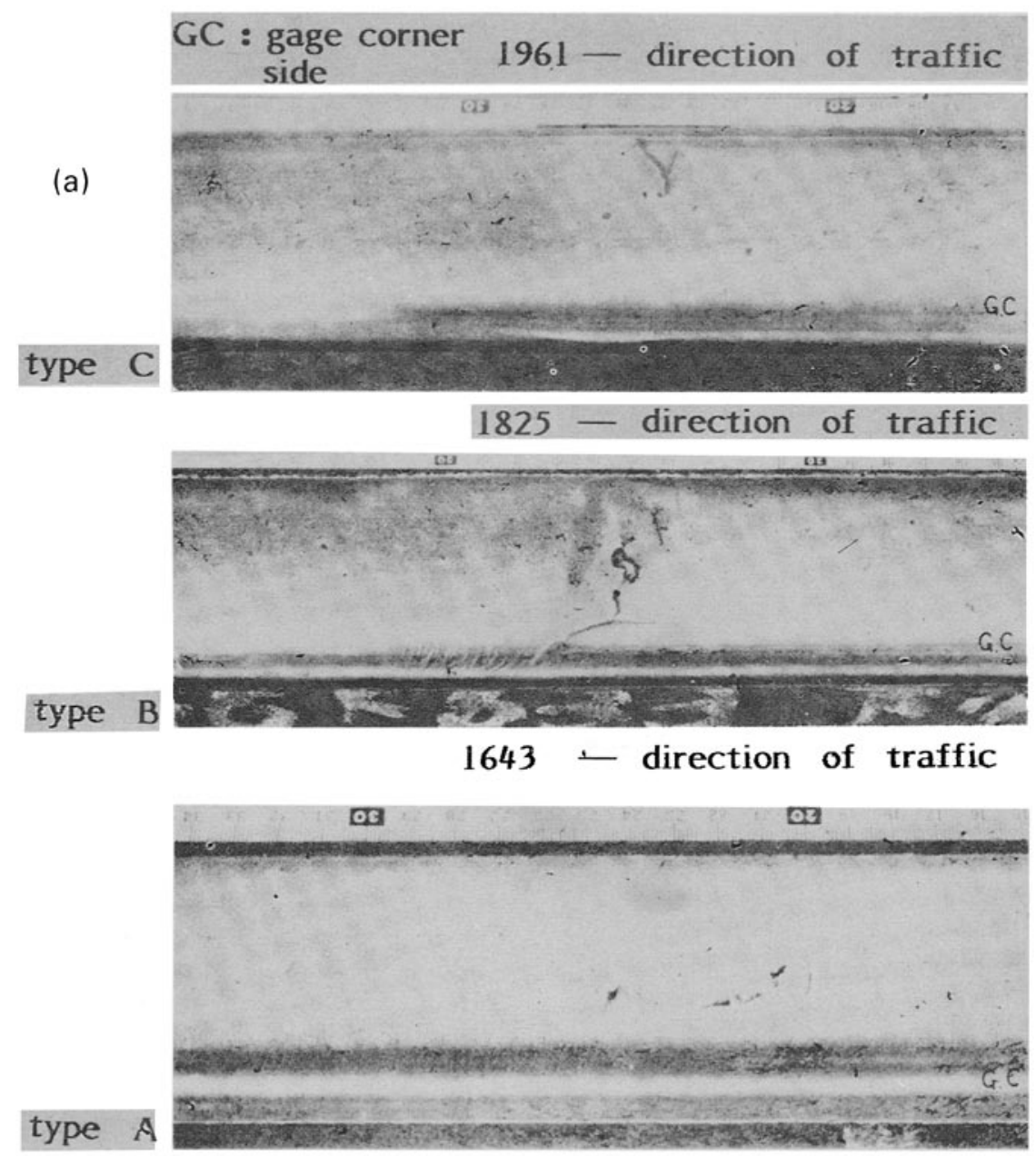

(b)

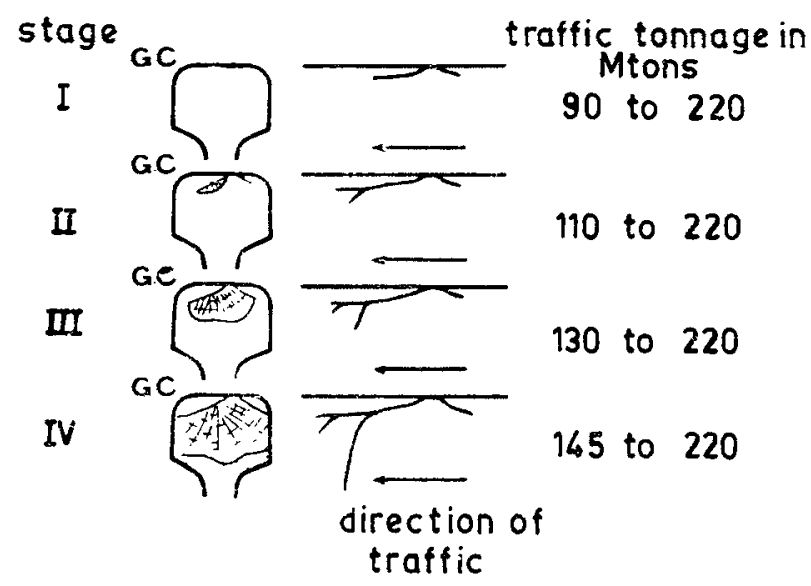

Figure 14. a) Macrophotograph depicting the formation of dark-spot on the running surface of rails; b) schematic sketch of propagation process involving dark-spots in different stages (Masumoto et al 1978, p. 233). 
horizontally. In successive stages, branching of cracks occurs and the number of branches goes on increasing in different stages. When the defect size covers about $70 \%$ of the rail head area, brittle fracture takes place in stage IV. At certain stages of crack propagation, a crack branch may take an upward turn leading to flaking. In general. branching occurs downward to facilitate vertical fissure.

From the above discussion it is apparent that dark-spots and head-checks are similar to shelling and are surface phenomena caused by contact rolling fatigue. Microstructural considerations suggest that fine pearlite prevents nucleation of cracks whereas tempered martensite obstructs its propagation. Though both contribute to increase in strength of rails, the former is preferred as crack initiation is drastically dalayed by its presence.

3.2e Corrugation: The appearance of a wave-like pattern on the running surface of rail is called corrugation (figure 15). Though not a serious service hazard, it impairs the riding quality of the track by introducing excessive vibration of rolling stocks. If not controlled, the depth of corrugation may go up to $1 \mathrm{~mm}$. Corrugation ilas been divided into short pitch and long pitch kinds, depending upon pitch length being less or more than $50 \mathrm{~mm}$, respectively (Taylor \& Crawley 1978).

Eisenmann (1978) has carried out detailed investigations on the formation of short pitch corrugation. The residual compressive stress built up during straightening and stress-reversal (Bauschinger Effect), together with compressive stress of the axle, produces bulging of the adjacent flow zone which corresponds to the crest of corrugation. The trough is formed in the pressure-relieved area where negative transverse or no strain is experienced.

An elegant review on the causes of corrugation has been made by Taylor \& Crawley (1978). Their own investigations have led them to conclude that train movement generates vibrations sufficient to deform the rail surface plastically. Correlation between track/vehicle resonance and the dominant corrugation pitch has been provided by Mair et al (1978). They showed that resistance to corrugation is directly proportional to the yield strength of rail steel. It should be noted that corrugation is more severe on curved tracks particularly in high side rails.

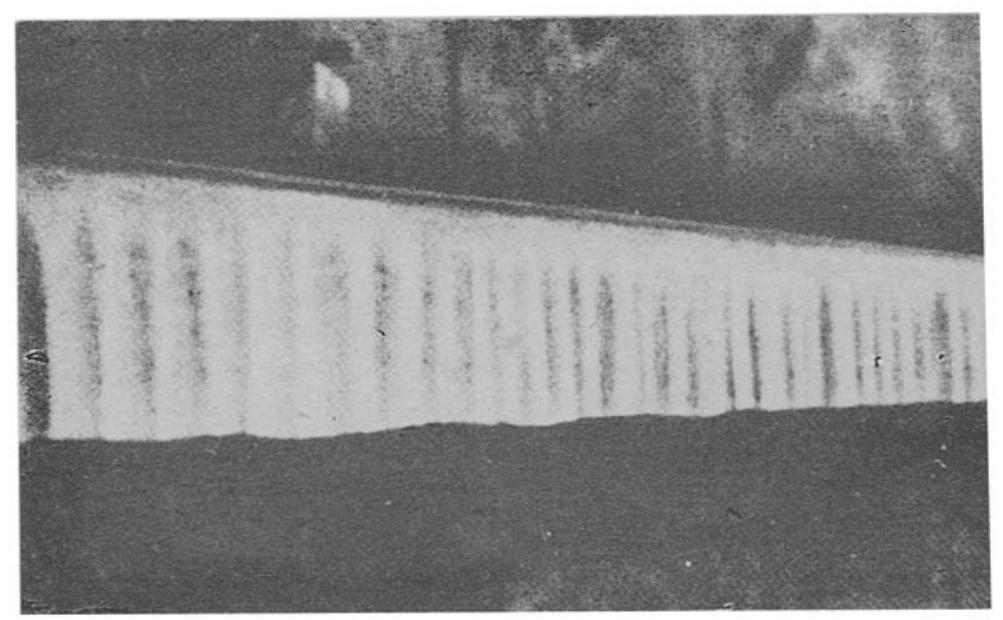

Figure 15. Macrophotograph showing corrugation in rails (Rail Defects Manual 1964). 
Macroexamination of severely corrugated rail head surfaces (peak to trough height $\approx 0.1 \mathrm{~mm}$ ) generally reveals very bright peaks. The valleys are exhibited as dull and often corroded regions. Metallographic investigations (Clayton \& Allery 1982) disclosed that troughs normally do not experience plastic deformation. In contrast, the presence of copious amounts of the white phase which is a transformation product and is extremely hard $(\approx 1000 \mathrm{HV})$ indicated excessive plastic deformation of crests. Profuse shearing of peaks along the direction of traffic has been commonly noticed. Microhardness measurement along longitudinal/vertical sections has been shown graphically in figures $16 \mathrm{a}, \mathrm{b}$. Figure 16́a exhibits microhardness variations through two consecutive peaks and troughs. It can be discerned that microhardness jumps from a base value of $\approx 250 \mathrm{HV}$ at the trough to $\approx 1000 \mathrm{HV}$ as the peak is approached, which is the characteristic hardness of a transformation product. The periodicity is about $60 \mathrm{~mm}$. Figure $16 \mathrm{~b}$ demonstrates that the base value of undeformed rails is reached at a depth of $\approx 200 \mu \mathrm{m}$. This indicates that sub-surface plastic deformation occurs up to a depth of $\approx 200 \mu \mathrm{m}$.
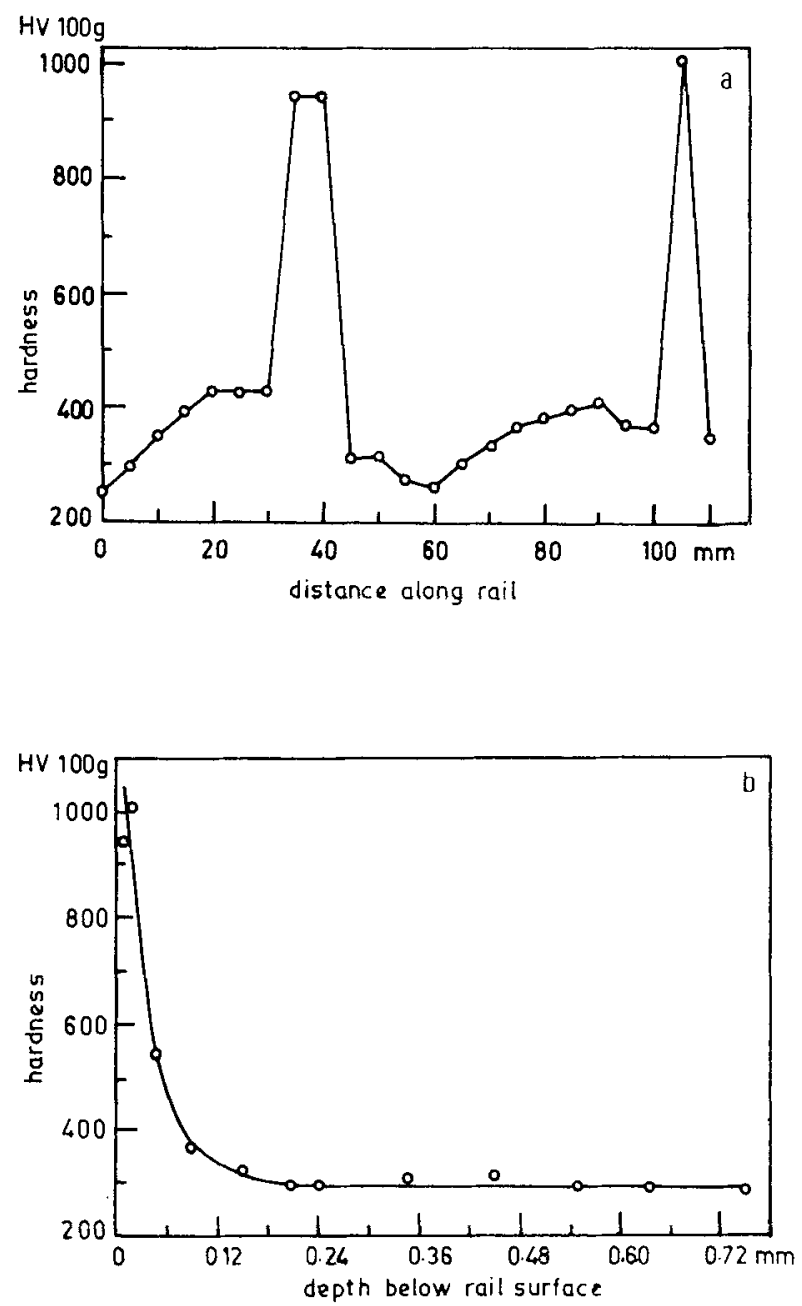

Figure 16. a) Microhardness traverse across longitudinal section at a depth of $20 \mu \mathrm{m}$ below the surface encompassing two corrugation peaks. The pitch is $\approx 60 \mathrm{~mm}$, b) microhardness traverse across the traverse section indicating the depth of plastic deformation at corrugation peak to be $\approx 200 \mu \mathrm{m}$ (Clayton \& Allery 1982). 


\section{Wear in rails}

Rails are brought into rubbing contact with wheels by rolling, sliding or impact. The roughness of the surface on the microscale produces forces which are concentrated on small areas around the asperity peaks. Large stresses are developed at these points resulting in the separation of materials in small quantities. Wear rate, a measurable entity, can be introduced to express loss of depth, area, volume or mass in appropriate units. The reciprocal of wear rate is referred to as wear resistance. It has been mentioned earlier that wear of rails is a serious problem. One of the effects is the increase in gauge length and the shift of contact points between rails and wheels. Furthermore, any change in rail-head profile accentuates the wear process due to nonadaptability of the rail-wheel contact surface.

\subsection{Wear mechanisms}

4.1a Corrosion-erosion: Tribochemical reactions between an activated surface experiencing sliding wear and environmental gases produce a surface layer which is loosely bound to the parent and material removal is facilitated by very small forces acting normal to the surface. Tribo-oxidation is one of the major causes of corrosive wear.

4.1b Abrasion: Abrasive wear results when a hard asperity indents a soft surface. A groove is cut as a result of relative motion between the surface and the asperity. The microchips removed during the cutting action further aid the wear process. Figure 17 shows a scar engraved by wheel asperity on the gauge corner of rails. The scar is as much as $20 \mu \mathrm{m}$ wide and $10 \mu \mathrm{m}$ deep (Kalousek \& Bethune 1978, p. 63).

4.1c Surface fatigue: Flaking and shelling of lower severity might result from contact fatigue. Chipping of these flakes causes rail wear.

4.1d Adhesion: Adhesion is bonding together of two metal surfaces in contact. Cold welded surfaces produced by adhesion under high stress often possess higher strength than the parent metals. Any sliding action will chip off such beads contributing to wear.

\subsection{Effect of microstructure on wear}

It has been established that high tensile strength and high hardness improve resistance to wear. Fine interlamellar spacing of pearlite tends to achieve both. Figure 18a shows the effect of hardness on wear rate of rail steels having different microstructures, viz, pearlite, tempered martensite and bainite. In all the cases, weight loss is reduced with increase in hardness. For identical hardness, pearlitic steel is the most wear-resistant whereas steel containing tempered martensite is the least. Ultimate tensile strength is inversely proportional to the square root of the interlamellar spacing of pearlite. Therefore, fine pearlitic rail steel is expected to have improved wear resistance as is evident from figure $18 \mathrm{~b}$. A regression analysis has been carried out by Ichinos et al (1978) wherein weight loss $(w)$ has been 


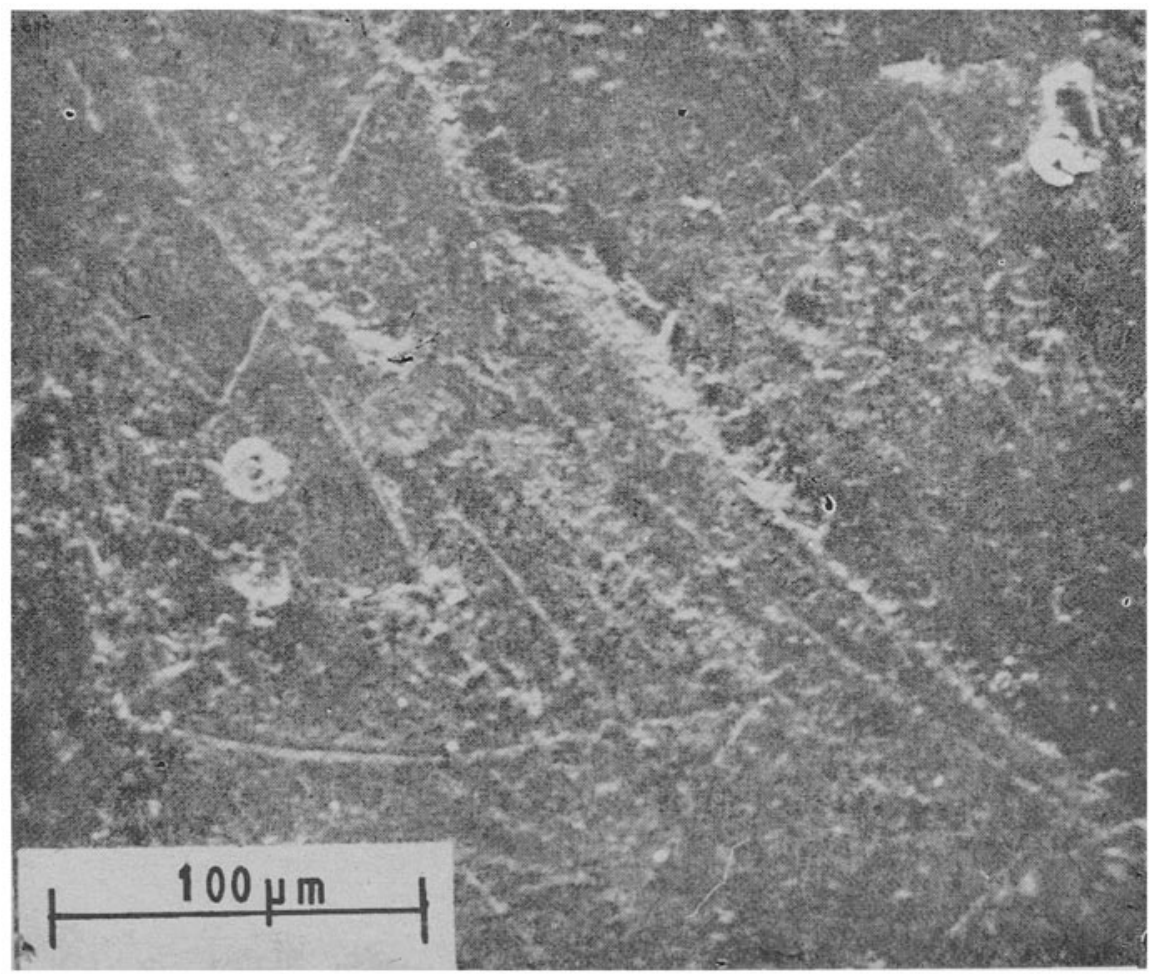

Figure 17. Scanning electron micrograph showing groove on rail surface cut out by wheel asperity (Kalousek \& Bethune 1978, p. 63).
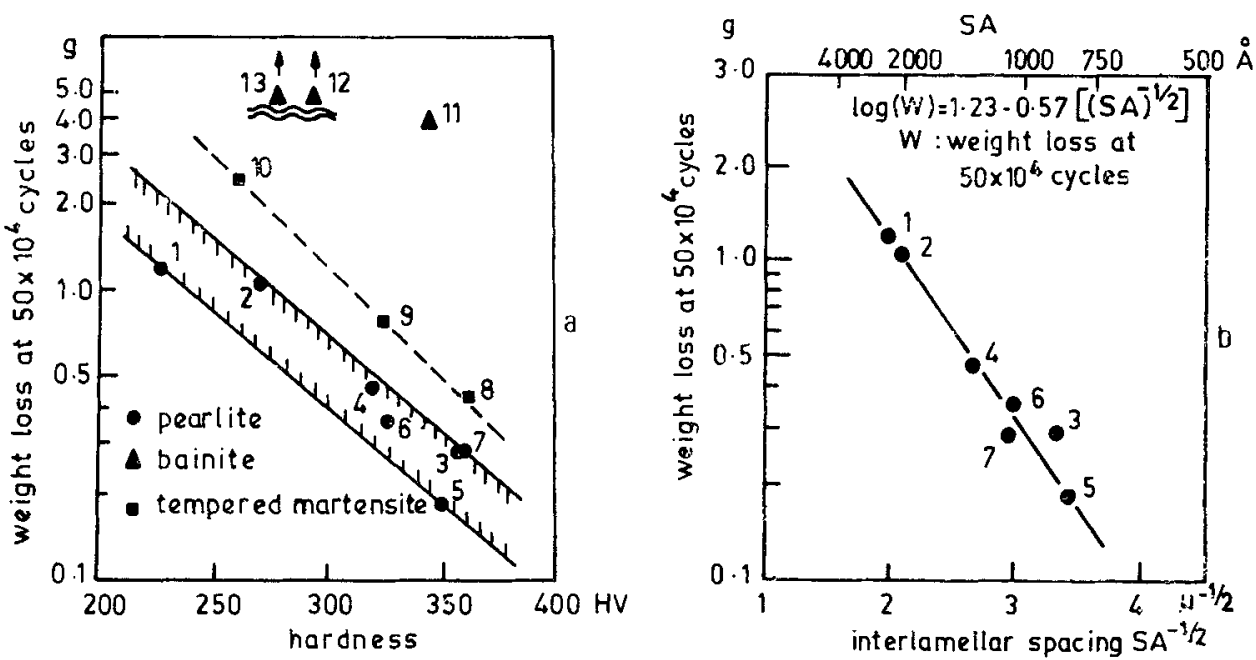

Figure 18. a) Influence of hardness and microstructure on the wear rate of rail steel; b) Effect of interlamellar spacing on the wear rate of pearlitic rail steel (Ichinos et al 1978). 
correlated to interlamellar spacing $\left(S_{A}\right)$ as: $\log w=1 \cdot 23-0 \cdot 57 /\left(S_{A}\right)^{1 / 2}$. Ichinos et al (1978) further showed that plastic deformation occurs up to a depth of $300 \mu \mathrm{m}$. A secondary structure, quite different from that in the matrix, forms in the sub-surface region. Fine pearlitic steel has a better wear-resistance as compared to bainitic steel and this is due to the difference in microstructure. In pearlitic steel the sub-surface microstructure consists of fine carbide particles formed as a result of the shearing of pearlite. These minute carbide particles are uniformly distributed and are difficult to separate by rolling contact. In bainitic steel the carbide particles, though globular, are randomly distributed. In addition, they are of larger size and their separation becomes easy resulting in decreased wear-resistance.

The nature of wear in in-service rails has been studied by Clayton \& Allery (1982). Visual observation disclosed bright running bands on the surface of worn rails. When viewed under the scanning electron microscope, the bright running band exhibited numerous laps generated as a result of plastic deformation and subsequent shear under the action of tractive forces. One of the possible mechanisms of rail-wear is the separation of these laps (figure 19). It has been contemplated further that the trailing edges of these laps act as sites for preferential corrosion which accentuates the wear process.

Metallographic examination of worn rails invariably revealed extensive plastic deformation of rail-head surfaces. Grain flattening was observed in the central region of the bright running band whereas edge portion showed shearing of grains

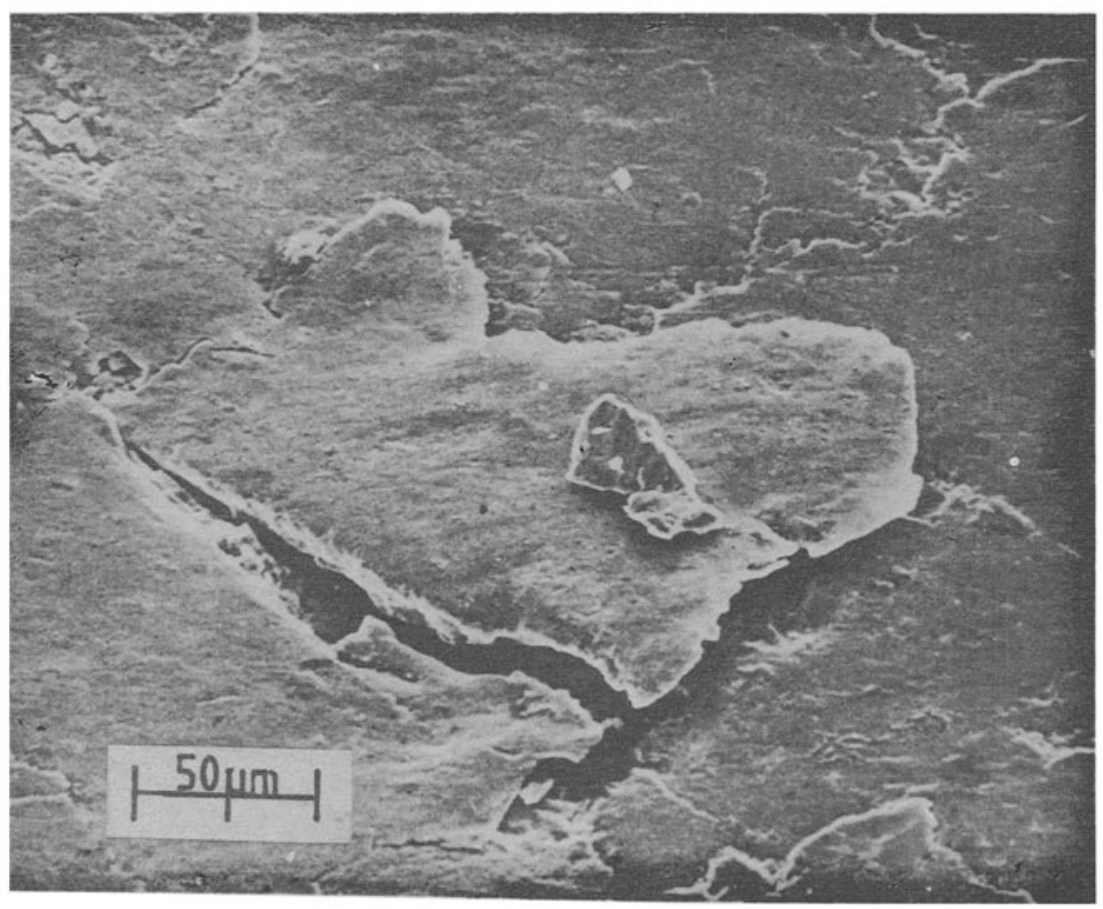

Figure 19. Scanning electron micrograph showing wear debris in the form of ruptured lap (Clayton \& Allery 1982). 


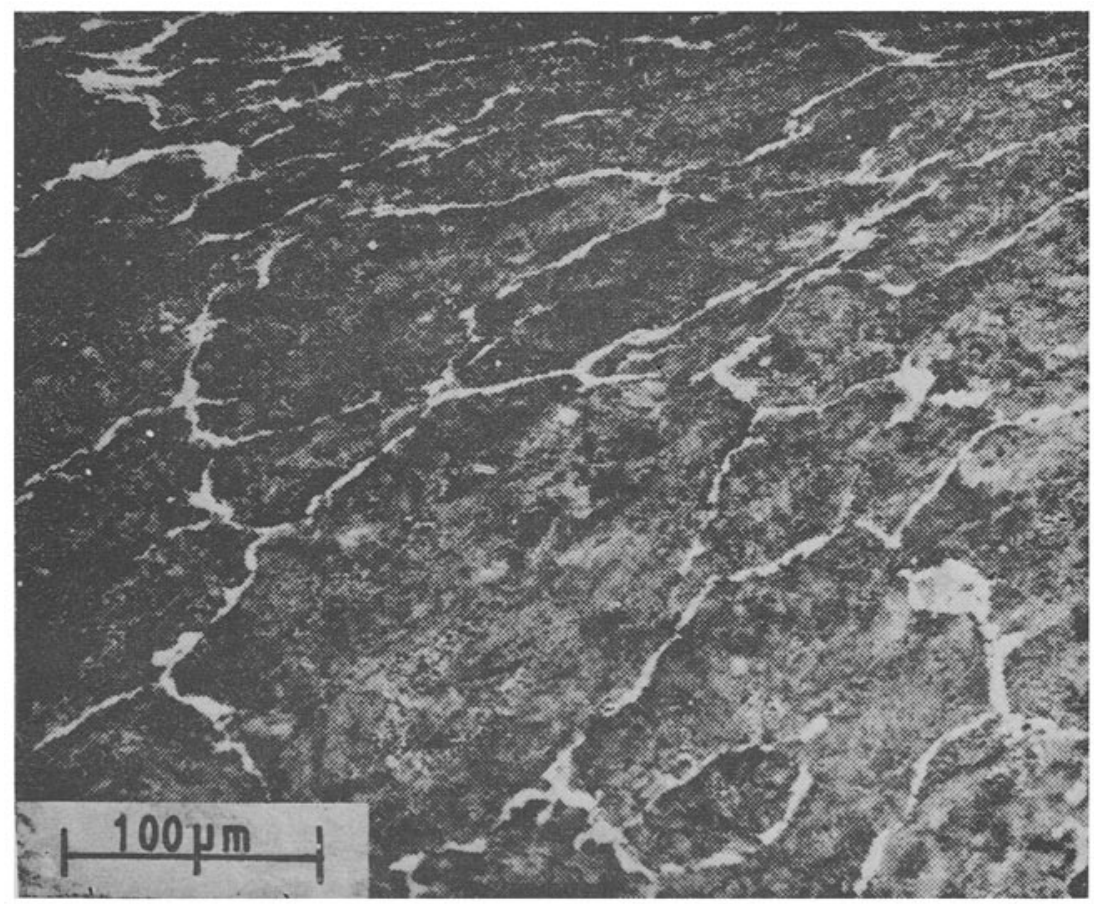

Figure 20. Optical photomicrograph showing flattening and shearing of grains as a result of plastic deformation (Clayton \& Allery 1982).

(figure 20). The depth of deformation was estimated by microhardness tests of transverse rail cross-sections. This varied from a mean of $\approx 520 \mu \mathrm{m}$ at the gauge corner to a mean of $\approx 330 \mu \mathrm{m}$ at the centre of the band indicating that the gauge corner undergoes maximum plastic deformation. The deformed pearlite had a maximum microhardness of $\approx 450 \mathrm{HV}$, about one and half times more than the base value $(\approx 300 \mathrm{HV})$.

One of the important observations made by Clayton \& Allery (1982) related to the presence of a very hard transformation product which they called 'white phase' (as described earlier in the context of corrugation). This was present in a majority of worn rails examined and its appearance varied from isolated islands to continuous surface layers. The continuous surface layer was formed by coalescence of oval regions of white phase.

The white phase was considered to be martensitic and it forms as a result of very short thermal cycling. However, theoretical considerations eliminate the possibility of achieving such a high temperature under normal wheel-rail contact. An investigation into the structure and property of this phase and also the reason for its formation may provide an insight into the process of wear in pearlitic rails.

\section{Concluding remarks}

In the foregoing, an attempt has been made to identify defects which commonly occur in rails during service. Among the defects generated during the processing of 
rails, hydrogen-induced shatter cracks have for long been recognized as the most detrimental. Unfortunately, the mechanism of flake nucleation and its subsequent growth is not completely understood and controversies persist to date. Also, the role of transformation stresses in flake formation needs to be decisively ascertained. Smialowsky (1962) has aptly summarized that, in order to determine the role of hydrogen in flake formation in steel, our knowledge of the hydrogen-iron system needs to be considerably expanded.

Optimisation of defect population often imposes conflicting requirements. Fatigue resistance of metals with inherent or service induced defects depends upon ductility and toughness properties while wear-resistance is related to ultimate tensile strength. In general, concurrent achievement of these two properties is difficult. It has been established that microstructural control through alloying and/or heat-treatment can produce rails having ultimate tensile strength twice that of normal rails and with improved ductility. Yield strength of rails becomes particularly important as most of the defects in service occur as a direct result of material at the running surface undergoing plastic deformation under the influence of tractive forces. The role of fracture mechanics in predicting the life of rails can not be overemphasized. It has become the lot of materials engineers to explore means for the arrest of the spread of cracks, either inherent during processing or initiated during service. Analysis of the causes of failure must be carried out extensively as it will serve as a future guide for minimizing premature failure. In addition, inspection techniques need to be improved so that even the smallest flaw that is susceptible to growth can be detected.

The authors are grateful to Shri H S Aswath for his encouragement and support.

\section{References}

Aichholzer W 1928 Stah! Eisen 48: 1332

Andrew J H, Bose A K, Lee H, Quarrell A G 1942 J. Iron Steel Inst. 146: 203

Bennek H, Schenck H, Miller H 1935 Stahl Eisen 55: 321

Clayton P, Allery M B P 1982 Can. Metall. Q. 21: 31

Cramer R E, Bast E C 1939a Am. Railw. Eng. Assoc., Froc. 40: 658

Cramer R E, Bast E C 1939b Trans. Am. Soc. Met. 27: 433

Cramer R E, Bast E C 1939c Trans. Am. Soc. Met. 27: 923

Dubovoi W Ya 1950 Flakes in steel (Flokeny $u$ Stali in Russian) (Moscow: Metallurgizdt)

Eisenmann J 1978 Proc, Heavy Haul Railway Conf, Inst. Engineers, Perth, Paper No. I-6: Session No. 413 413

Heller E, Weber L, Hammerschmid P, Schwitzer R 1972 Stahl Eisen 92: 934

Ichinos H, Takahara J. Iwasaki N, Ueda M 1978 Proc. Heavy Haul Railway Conf., Inst. Engineers, Perth, Paper No. I.3; Session No. 307

Kalousek J, Bethune A E 1978 in Rail steels - development, processing and use, ASTM STP 644 (eds) D H Stone, G G Knupp (Philadelphia: Am. Soc. for Testing and Materials)

Knupp G G, Chidley W H, Giove J L, Martman H H, Morris G F, Taylor C W 1978 in Rail steels - development, processing and use, ASTM STP 644 (eds) D H Stone, G G Knupp (Philadelphia: Am. Soc. for Testing and Materials)

Kumar S, Rajkumar B R 1980 Am. Railw. Eng. Assoc., Bull. No. 679

Kumar S, Aronov V, Rajkumar B R, Márgasahayam R 1982 Can. Metall. Q. 21: 56

Mair R I, Jupp R A, Groenhout R 1978 Proc. Heavy Haul Railway Conf., Inst. Engineers, Perth, Paper No.1.6, Session No. 417 
Marich S 1979 Proceedings of the seminar on vanadium in rail steels (London: Vanitec Publications) Marich S, Cottam J W, Curcio P 1978 Proc. Heavy Haul Railway Conf., Inst. Engineers, Perth, Paper No. I.1, Session No. 303

Masumoto H, Sugino K, Nisida N, Kupihara R, Matsuyana S 1978 in Rail steels - development, processing and use, ASTM STP 644 (eds) D H Stone, G G Knupp (Philadelphia: Am. Soc. for Testing and Materials)

McGannan H E (ed.) 1964 The making, shaping and treating of steels 8th edn (Pittsburgh: US Steels)

Meskin V S 1950 Stahl 8: 727

Rail Defects Manual 1964 Sperry Rail Service, Danbury, Conn., USA

Scharader H, Pranjape V G 1954 The Manager TISCO Rev. 1: 13

Smialowski M 1962 Hydrogen in steels (Oxford: Pergamon)

Sonnon D E, Pallegrino J V, Wandrisco J M 1978 in Rail steel - development, processing and use, ASTM STP 044 (eds) D H Stone, G G Knupp (Philadelphia: Am. Soc. for Testing and Materials)

Stone D H, Steels R K 1978 in Rail steels - development, processing and use, ASTM STP 644 (eds) D H Stone, G G Knupp (Philadelphia: Am. Soc. for Testing and Materials)

Taylor J B C, Crawley A M 1978 Proc. Heavy Haul Railway Conf., Inst. Engineers, Perth, Paper No. 1.7, Session No. 416 